\title{
Anastomosing Hemangioma
}

National Cancer Institute

\section{Source}

National Cancer Institute. Anastomosing Hemangioma. NCI Thesaurus. Code 1131760.

An unusual variant of capillary hemangioma. It is characterized by a unique anastomosing sinusoidal-like architecture which may mimic angiosarcoma. It was originally described in the kidney but rare cases have been reported in other sites. 